\title{
DESIGN GRÁFICO INCLUSIVO APLICADO A MATERIAIS INSTRUCIONAIS: ESTUDO DE CASO
}

Julia Yuri Landim Goya

FAAC - UNESP

jylgoya@hotmail.com

Cassia Leticia Carrara Domiciano

FAAC - UNESP

cassiacarrara@gmail.com

Resumo: Este artigo apresenta os resultados de uma pesquisa de iniciação científica sobre as áreas do Design Inclusivo e do Design Instrucional, e sob essa ótica, uma análise das necessidades em Design Gráfico impresso, digital e audiovisual (cartilhas, manuais,entre outros materiais instrucionais de uso em atendimento, como cartazes e figuras), em clínicas de atendimento a pacientes com distúrbios de aprendizado e de comunicação. Este levantamento visa a construção de um grande brefing projetual, onde os problemas serão considerados para uma ação posterior coordenada pelo grupo de pesquisa de investigação e prática em design gráfico inclusivo para a criação ou aprimoramento dos materiais.

Palavras-chave: design informacional, design gráfico, design inclusivo, materiais instrucionais.

Resumo: This paper presents the results of a scientific initiation research on areas of Inclusive and Instructional Design, and, from this perspective, an analysis of the needs in printed, digital and audiovisual materials (brochures, manuals, for use in service such as posters and pictures) in clinical care to patients with learning and communication disorders. This survey aims to build a large briefing projetual where the problems will be considered for further action coordinated research and practice in inclusive graphic design.

Palavras-chave: informacional design, graphic design, inclusive design, instrucional materials. 


\section{INTRODUÇÃO}

Podemos considerar que a capacidade do designer realizar projetos inclusivos depende de seu contexto social de projeto. Por outro lado, a realização de um projeto envolve uma competência que não é apenas formal/visual, mas, sobretudo, de articulação de um conceito de artefato, que necessariamente envolve a síntese formal/visual (Lasse, 2009).

O design, para Gomes Filho (2003), é uma ferramenta com a qual se pode contar para melhorar o padrão de qualidade de objetos. Essas qualidades são planejadas, concebidas, especificadas e determinadas, aliadas à tecnologia e aos processos de sua produção. Já Löbach (2001) afirma que "o conhecimento de um fato ou problema é uma das condições necessárias à atividade do designer industrial. Por isso, é da maior importância, para alcançar a solução de um problema, reunir e analisar todas as informações disponíveis." Esse processo de solução de problemas determinará uma sequência de etapas em que o designer irá tratar da necessidade, em todas as suas nuances, finalizando com um produto que atenda à satisfação do cliente.

Para Fenner (2000), autora focada na área da educação, o design é uma "ação inovadora que cuida das necessidades de uma comunidade de usuários, tendo como meta a concepção de produtos e serviços que as atendam.". Como a interação entre usuário e produto deve considerar a capacidade cognitiva humana com um ambiente de trabalho de acordo com sua realidade e com uma usabilidade adequada, o design deve promover o "desenvolvimento de material didático tecnológico" que norteie o gerenciamento de produtos para a educação. A autora também compila alguns requisitos nos quais o designer gráfico se ocupa em seus projetos: ter capacidade criativa, com propostas inovadoras com domínio de técnicas e processos de criação; dominar a linguagem, as técnicas de expressão e reprodução visual em diferentes mídias; saber dialogar com especialistas diversos; ter visão sistêmica de projeto; conhecer metodologias de desenvolvimento de projetos; conhecer o setor produtivo de sua especialidade; conhecer noções de gerenciamento de produção, em seus diversos segmentos, e ter visão histórica dos acontecimentos políticos, socioeconômicos, éticos e antropológicos gerais.

Campos e Vasconcellos (2011) acreditam que é possível entender o design como uma prática que incorpora em seu fazer a natureza criativa e inovadora, e que exige exercícios de imaginação, criação, inventividade, sem entretanto, perder a visualização das necessidades, oportunidades e dificuldades dos processos de produção e comunicação.

Por outro lado Fujita ET AL (2007) nos recorda que apesar da importância dos aspectos gráficos que influenciam na leitura e compreensão pouco se tem investigado sobre este tema, particularmente sob a ótica do design gráfico. A autora também afirma que o não suprimento das necessidades informacionais e a falta de experiência do leitor com a informação podem levar à incompreensão de seu conteúdo e, portanto, influenciar negativamente o desempenho na execução de tarefas relacionadas a um produto.

Villas Boas (2009) também ressalta a importância do olhar crítico no ato projetual. Ao se posicionar como analista crítico de um projeto, o estudante ou profissional se vê frente a variáveis que tende a considerar próprias da prática, por estar lidando com um layout, seja ele impresso ou reproduzido digitalmente e com as implicações que ele carrega. Mas se a análise for consequente e minimamente 
aprofundada, terá de recorrer ao universo que se tende a associar ao campo da teoria. Para que ela seja realizada de maneira consistente e consequente, é necessário que o sujeito da análise compreenda a lógica interna de seu objeto. Sem isto, a análise fatalmente estará condicionada por preconceitos e se mostrará sem sentido.

Portanto, é papel do design também se preocupar como todas essas produções serão lidas e por quem serão entendidas. Qualquer material deve gerar um nível de compreensão para diferentes leitores e daí então a importância de um design gráfico mais inclusivo. Afinal todas as informações em produtos, placas, embalagens, livros, nos informam coisas que devem ser lidas de uma maneira correta para sua interpretação mais coerente.

\section{OBJETIVOS}

Esta pesquisa de iniciação científica deu início a um projeto que se traçou para o atendimento das necessidades em design gráfico das clínicas da FOB-USP (aplicáveis posteriormente a outros centros e instituições), numa visão da inclusão. Teve como objetivo geral desenvolver uma pesquisa teórica sobre as citadas áreas do design gráfico Inclusivo e do design instrucional, necessária aos pesquisadores do grupo de pesquisa "Design Gráfico Inclusivo: visão, audição e linguagem", que conta com diversos professores doutores, alunos de doutorado, mestrado e diversos alunos de iniciação científica, incluindo-se as autoras.

Assim, delimitamos ainda um objetivo posterior: levantar junto aos profissionais e orientadores das clínicas da FOB-USP do Centro de Pesquisas Audiológicas - HRAC/USP,que se debruçam ao estudo e tratamento de distúrbios da audição e da linguagem, as necessidades em design gráfico, sejam de produtos impressos (cartilhas, manuais, materiais instrucionais de uso em atendimento, como cartazes e figuras, por exemplo) audiovisuais ou digitais (AVAs, CD-Roons, vídeos, entre outros). Este levantamento visa a construção de um grande breafing projetual, onde os problemas serão considerados pra uma ação posterior coordenada de investigação e prática em design gráfico inclusivo.

\section{METODOLOGIA}

Para que o primeiro objetivo proposto fosse atingido, foi feita uma pesquisa bibliográfica. Segundo Lakatos\&Marconi (2009), uma pesquisa dessa natureza deve contar com uma organização sistemática dos conteúdos levantados e uma posterior análise e interpretação.

Num segundo momento da investigação, foram realizadas reuniões com os profissionais e visitas às Clínicas de Fonoaudiologia da FOB-USP especificamente aquelas que trabalham com dois tipos de distúrbios: auditivos e de linguagem particularmente a leitura e escrita. Um levantamento de problemas e um breafing foram feitos, considerando-se as metodologias de projeto em design gráfico (Fuentes, 2009; Lupton\&Phillips, 2008; Samara, 2007 e 2010). Para tal levantamento, a observação e entrevistas semi-estruturadas apontaram como os melhores procedimentos. 


\section{PRESSUPOSTOS TEÓRICOS LEVANTADOS}

Delimitou-se mapear melhor os estudos nas áreas citadas: design instrucional e o design inclusivo, focados no design gráfico. Além de uma bibliografia mais consagrada, pesquisas recentes e artigos foram considerados, uma vez que vivemos um momento profícuo de produção científica em design. Segue-se um resumo deste levantamento.

\subsection{Design gráfico}

Compor um produto de design gráfico é estruturar e organizar os elementos visuais, como por exemplo, cores, textos, imagens, entre outros, e determinar a importância e a funcionalidade estética de cada um deles no layout. Para que essa organização possa ser obtida e a mensagem compreendida, faz-se uso de algumas estratégias, como uso de grids, criação de ritmo, equilíbrio, contraste, escala, entre outras, os quais são a base para constituir um leiaute. O designer, de acordo com a intenção da comunicação, determina a sequência de leitura cujos elementos de maior importância recebem um destaque maior e dirigem o olhar do receptor para as informações complementares. Pode-se afirmar que uma das funções da composição é auxiliar na estrutura e organização de um projeto em que as informações devem ser dispostas de forma que as de maior importância sejam percebidas primeiro pelo olhar do receptor que, em seguida, se dirige às informações complementares.

Porém Dondis (2003) reflete que não há regras absolutas, mas sim, um grau de compreensão do que vai acontecer em termos de significado. $O$ designer tem inúmeros elementos, ferramentas e técnicas à sua disposição, mas tudo depende do seu conhecimento e intenção. A mensagem passa a ser construída na composição por meio das cores, tipografias, alinhamentos, contrastes, entre outros recursos. As diferentes combinações dos diversos elementos compositivos geram uma série de significados, constroem atmosferas variadas e, além de determinarem o sentido de leitura, enfatizam a proposta do projeto. A autora resume dizendo que criamos um design a partir de inúmeras cores e formas, texturas, tons e proporções relativas; relacionamos interativamente esses elementos; afinal temos em vista um significado.

Com base nos fundamentos visuais, táteis e espaciais da forma, algumas de suas características tais como a cor, a luz, os materiais, a textura, ganham autonomia analítica. Além disso, podemos citar Lasse (2009) que enumera outras como caracterizações operativas, interativas e de agenciamento espacial; hibridizações técnicas, envolvendo modelização matemática e captação de dados da realidade; hibridizações técnicas e de linguagem considerando o formal/visual associado a outras bases de linguagens, a incorporação da percepção temporal por meio de estruturas narrativas e outros recursos.

Lasse (2009) também nos lembra que, na medida em que acontece uma mudança tecnológica, há também uma mudança na cultura material; como em termos de formatações utilitárias, em termos de ocorrências formais e visuais mais elementares, em termos de conceitos associados a esta nova realidade, em termos de desdobramentos tecnológicos e consequências sociais correspondentes e em termos do controle social do conhecimento.

\subsection{Design inclusivo}

Hudson (2004) apresenta a expressão design inclusivo, como alternativa a "acessibilidade", para expressar o foco em usabilidade para uma faixa mais ampla da 
população, que leva em consideração as deficiências e aspectos relacionados à idade da população. Já para Keates e Clarkson (2003) e Keates et al (2000) consideram os usuários em suas diferentes capacidades perceptuais, cognitivas e motoras, a partir de uma maior consciência da exclusão que determinadas propostas e projetos de design podem provocar e do impacto das decisões tomadas durante o desenvolvimento do produto que poderiam levar à exclusão do público-alvo. Por outro lado Newell e Gregor (2000) sugerem o desenvolvimento de um "Design Inclusivo Sensível ao Usuário", que inclui pessoas com deficiências dentro de uma metodologia. Os usuários com deficiência, neste caso, atuariam principalmente como avaliadores de protótipos e de soluções de design. Segundo os autores a expressão "sensível ao usuário" substitui o "centrado no usuário" para enfatizar a dificuldade extra envolvida quando o intervalo de funcionalidades e características dos grupos de usuários pode ser tão grande que se torna impossível produzir uma amostra representativa do grupo de usuários.

Para Melo\&Baranauskas (2006) o conceito de design inclusivo tem suas raízes no entendimento da palavra "inclusão". Inclusão diz respeito ao convívio com as diferenças, considerando que todas as pessoas são diferentes entre si e devem ser respeitadas em seus direitos, inclusive aqueles relativos ao acesso à informação e à participação em sociedade. Entre as diferentes manifestações das diferenças, estão as deficiências perceptuais, cognitivas e motoras, que podem ser permanentes ou temporárias, ocorrerem sozinhas ou combinadas. Ao considerar a participação das pessoas em ambientes inclusivos de design, os materiais, os métodos de trabalho e a atitude das pessoas precisam ser abertos e flexíveis de maneira a não promover a exclusão e a discriminação.

Existem princípios de usabilidade e design que devem ser analisados ao projetar um artefato, são eles: visibilidade, retro-alimentação auditiva, tátil, visual e combinações entre elas, restrições físicas, lógicas e culturais, mapeamento, consistência e propiciação percebida e real. A usabilidade está diretamente ligada ao diálogo na interface e traduz-se pela capacidade que o objeto possui em permitir ao usuário o alcance de suas metas de interação. A facilidade de aprendizagem, a efetividade, a atitude, a flexibilidade, a utilidade percebida do produto, a adequação à tarefa e as características da tarefa e dos usuários são os principais fatores relacionados à abrangência do termo usabilidade.

A maioria dos autores que trabalham com design inclusivo citam como solucionar ambientes e modificar produtos, assim como a criação de parâmetros e inclusive leis para a construção dos mesmos. Apesar do alto número de acidentes e desconfortos que ocorrem em nosso dia a dia devido a ruídos na comunicação e problemas na interpretação das informações, ainda damos mais importância a produtos do que em aspectos visuais.

Existem sim trabalhos que envolvem deficientes visuais, distúrbios de atenção, idosos e outras pequenas parcelas da sociedade. Porém o design gráfico inclusivo ainda não recebe a total atenção, por exemplo, no campo da ergonomia. Ao pesquisar parâmetros de construção de materiais gráficos há uma preocupação muito mais estética e inovação do que a preocupação se as informações passadas estão sendo interpretadas corretamente.

Talvez a realidade de que produtos gráficos sejam, em parte, descartáveis, deva ter levado os pesquisadores e designers a não refletir tanto sobre a sua acessibilidade 
quanto em produtos físicos e mais duráveis. Porém com o aumento da preocupação de atender estes pequenos núcleos da sociedade, o design gráfico inclusivo, tem aumentado seu campo de estudo nas últimas duas décadas.

$\mathrm{O}$ advento da tecnologia neste quesito acelerou este processo, pois materiais gráficos digitais tem, cada vez mais, causado constrangimento ao usuário tanto quanto uma cadeira ou um ônibus. Portanto, a maioria das pesquisas nesta área é focada em materiais digitais, como podemos ver na área de design Instrucional.

Ainda há a necessidade de uma análise extensa de produtos mistos, como embalagens que abrangem tanto o projeto gráfico quanto produto, e de produtos puramente gráficos como livros, anúncios, sinalização e assim por diante. Devemos lembrar que estes materiais são feitos para grande parcela da população, não apenas para idosos ou deficientes visuais e, portanto devem ser acessíveis.

\subsection{Design instrucional}

O texto, ou informação, não pode ser fixado às interpretações de mundo de seu autor ou criador, nem aos atos da seleção e da combinação, nem aos processos de formação de sentido que acontecem na sua elaboração. $O$ texto, e qualquer outro tipo de informação, faz parte de um processo integral que abrange desde a reação do autor ao mundo até sua experiência pelo leitor. No ato da leitura o leitor realiza várias conexões mentais, deste modo, a própria associação de pensamentos acontece, de certa forma, em rede e não de maneira linear. Portanto não podemos assumir que o público leitor terá a mesma interpretação que nós, designers criadores, tivemos. (FARBIARZ et al, 2006)

O design instrucional é capaz de abordar e elaborar estratégias para consolidar uma relação de ensino-aprendizagem entre sujeitos. Também é identificado como uma metodologia educacional capaz de se valer da tecnologia para propor práticas e soluções para uma aprendizagem colaborativa, autônoma, que atenda às novas demandas da sociedade da informação. (BATISTA E MENEZES, 2008)

A noção que o design informacional abrange a integração do trabalho de designers instrucionais, designers gráficos, instrutores, gerentes e outros profissionais através de um processo de trabalho sistemático. Filatro (2004) define o design como responsável pelas funções internas de um produto, trazendo-as à superfície visualmente, e também em diferentes níveis e formas: através dos modos sensoriais (cores, formas, texturas, sons), e dos modos cognitivos (linguagem, metáforas, hipertexto, mapas conceituais, realidade virtual, entre outros). 0 design instrucional não se reduz à face visível de produtos instrucionais, nem se refere apenas a um planejamento abstrato de ensino, mas reflete a articulação entre forma e função, a fim de que se cumpram os objetivos educacionais e informacionais propostos.

O campo de atuação do designer instrucional então pode ser caracterizado como responsável pela complexidade do conteúdo tratado, e pela síntese do mesmo, ou seja, o profissional instituído como designer instrucional deve ser compreendido em termos de forma e funcionalidade, com propósitos e intenções bem-definidos. (FILATRO, 2004)

O design instrucional também é visto como uma área da pesquisa educacional que estuda formas de ajudar as pessoas a aprenderem melhor. Neste caso também é chamado de design pedagógico. A área envolve a metodologia voltada ao planejamento de currículos, programas de capacitação e de materiais didáticos em 
diferentes mídias e contextos de aprendizagem. A intenção dessa área de pesquisa é a realização de um planejamento sistemático, baseado em princípios científicos de comunicação, aprendizagem e de ensino que melhorem os materiais instrucionais elaborados. Ele deve permitir que os materiais didáticos sejam contextualizados, levando-se em conta diferentes aspectos. Esses envolvem, de acordo com FILATRO e PICONEZ (2004):

- Personalização aos estilos e ritmos individuais de aprendizagem;

- Adaptação às características institucionais e regionais;

- Atualização a partir de feedback constante;

- Acesso a informações e a experiências externas à organização de ensino;

- Possibilidade de comunicação entre os agentes do processo (alunos tutores, professores, coordenadores);

- Monitoramento automático da construção individual e coletiva de conhecimento.

Essa competência prevê que o designer instrucional deve, além de estabelecer a conexão com conteúdos, objetivos e estratégias instrucionais, também produzir materiais instrucionais em diversos formatos de apresentação. Para o desenvolvimento de cada um desses materiais instrucionais, há a necessidade de competências específicas, como é o caso do webdesigner (profissional responsável pelas tecnologias interativas), ou do designer gráfico, que tem sua formação bem fundamentada quanto às estratégias de programação visual de materiais impressos, além das pesquisas recentes sobre a relação do design e emoção. (BATISTA E MENEZES, 2008)

Tractenberg (2007) apresenta o Design Instrucional como um processo sistemático e reflexivo de traduzir princípios de cognição e aprendizagem para o planejamento de materiais didáticos, atividades, fontes de informação e processos de avaliação. Sua prática se orienta por resultados de pesquisas principalmente na área de Educação, Psicologia e Comunicação. Trata-se de uma abordagem sistêmica, que pondera múltiplos fatores que afetam e/ou podem ser afetados pela implementação de uma iniciativa de educação ou treinamento.

\section{PESQUISA DE CAMPO}

Com o intuito de levantar junto a profissionais das clínicas da FOB-USP os tipos de materiais instrucionais (cartilhas, manuais, materiais instrucionais de uso em atendimento, como cartazes e figuras, entre outros) e qualidade dos mesmos, foi feito um levantamento de problema via entrevistas informais para gerar um briefing projetual para ações futuras.

Sendo assim, foram realizadas reuniões com os profissionais e visitas às Clínicas de Fonoaudiologia da FOB-USP especificamente aquelas que trabalham com dois tipos de distúrbios: auditivos e de linguagem - particularmente a leitura e escrita. 0 levantamento de problemas e indicações de possíveis soluções foi feito para gerar o briefing. Para tal levantamento, a observação e entrevistas semi-estruturadas apontaram como os melhores procedimentos. 
Para que este objetivo fosse atingido, optou-se pela realização de entrevista estruturada com os profissionais da clínica de Fonoaudiologia da USP. Desenvolveu-se um questionário visando detectar:

- Perfil de pacientes

- Perfil dos profissionais

- Conhecimento dos profissionais sobre tema abordado

- Levantamento de necessidades em design gráfico

Neste sentido, elaboraram-se perguntas específicas a serem dirigidas aos entrevistados, a saber:

1. Qual o perfil dos pacientes atendidos na clínica?

2. Há quanto tempo trabalha na clínica?

3. O que você entende por Design Instrucional? Pode dar exemplos?

4. Você utiliza algum material instrucional? Se sim, qual?

5. Estes materiais utilizados ajudam no seu trabalho? São adequados ou já causaram alguma confusão na comunicação da informação? Como poderiam ser melhorados?

6. Existem outros materiais instrucionais que você consideraria interessantes, porém que não possua na clínica ou que não tenha sido confeccionado (não "exista")?

No dia 15/06/2015 a primeira visita foi realizada na Clínica de Fonoaudiologia, coordenada pela livre-docente Patrícia Abreu Pinheiro Crenitte, que atua na clínica desde 1991 e estuda linguagem em sua forma oral e escrita, especialista na área de distúrbios de linguagem. Além da Professora Patrícia, foram entrevistadas 5 alunas de graduação da fonoaudiologia da USP, que cursando o terceiro ano em diante e que atendiam na clínica há, no mínimo, seis meses e, no máximo, um ano e meio.

De maneira geral elas não souberam identificar o termo "Design Instrucional", porém quando insistido para que supusessem, disseram que era algo relacionado a desenho e a design gráfico, que era uma área que gerava modificações nos desenhos e informações para quem vê ou uma ferramenta para aplicar e melhorar a compreensão ou a forma que se trabalha, também relacionaram como uma avaliação de manuais.

O termo foi então explicado, dando-se exemplos, como manuais de instrução, versos de embalagens e qualquer outro material gráfico que possuíssem instruções de manuseio. Posteriormente, indagou-se sobre exemplos de materiais instrucionais usados na clínica.

As entrevistadas deram exemplos: jogos com instruções, slides das professoras que explicam como aplicar testes, cartilhas para pacientes com deficiência auditiva, uma fotocópia das telas de um software que explica passo a passo como aplicar um teste, livros de como aplicar ou corrigir certos testes, folhetos e folders de como manusear aparelhos, instruções nas salas sobre seu uso e higienização, folhetos de normas da clínica, materiais para os pacientes e placas de indicações e sinalização.

Elas consideraram, de maneira geral, os materiais efetivos, mas ressaltaram que poderiam ser sem dúvidas melhorados. Entre as melhoras foram apontadas: transformar o material em algo mais didático, colocar mais informações sobre casos raros (a maioria dos manuais apenas possuem os erros comuns), o acompanhamento 
de um profissional da área do design para analisar e inferir sobre os materiais utilizados, tornando-os mais atrativos e visíveis, incluindo-se aí um sistema de sinalização mais eficiente.

A entrevista e visitas levaram ainda ao levantamento de materiais não utilizados, mas que seriam importantes para um incremento do atendimento, como jogos, materiais digitais e manuais de instrução não apenas para pacientes e pais, mas também sobre o atendimento na clínica e aplicação de testes, ou seja, para os profissionais.

\section{RESULTADOS E CONSIDERAÇÕES}

Com os dados coletados das entrevistas e analise visual do local e alguns materiais dispersos pela clinica, pode-se notar que não há a presença de um profissional atuando junto com a equipe da clínica. Como foi comentado por uma das entrevistadas é interessante que alguém da área faça esse acompanhamento para a melhoria dos materiais e eficácia dos mesmos.

Notaram de maneira geral a importância desse profissional para a melhoria dos materiais presentes na clínica, tanto no momento de atendimento, quanto no dia a dia em aulas e sinalização ou instruções gráficas para elas, não apenas para os pacientes. Sendo assim, o designer deve assumir seu papel de importância em campos diferenciados e enxergar o poder da inclusão via o design gráfico e instrucional.

De maneira geral os maiores problemas relacionados foram a falta de pregnância dos materiais, uma vez que a maioria apresentava-se sem cor e portanto não chamava atenção ou era considerado enfadonho. O uso de cores seria uma possível solução neste caso, mas com o devido discernimento, pois havia materiais extremamente coloridos, porém relativamente ilegíveis.

Constata-se também a necessidade de um estudo mais profundo do público alvo destes materiais instrucionais, para que possam ser mais bem atendidos. A partir daí deve-se verificar se é necessário o desenvolvimento de materiais para grupos específicos de usuários.

A organização interna da clínica, como a sinalização, bem como as instruções que são dadas aos funcionários também necessita de uma padronização: a falta de atenção e conhecimento destes materiais instrucionais pode levar a erros no dia a dia, prejudicando o funcionamento da clínica. Neste caso, seria necessário um levantamento dos tipos de testes que normalmente precisam de instruções antes de ser aplicados, verificando-se a necessidade ou não de materiais diferenciados para eles; a sinalização também afeta os pacientes, afinal foi comentado que somente quem trabalha no local sabe que sala serve para qual atividade.

Diante do exposto, destaca-se a necessidade da valorização do design gráfico atuando nas áreas analisadas, uma vez que a função de instruir e comunicar são de absoluta importância na área da saúde, dependendo destas o bom andamento de tratamentos médicos e, em alguns casos, a vida das pessoas. $O$ envolvimento de designers nesse processo reforça o papel social, na inclusão e na melhoria da vida das pessoas que o design deve assumir.

\section{AGRADECIMENTOS}

Ao CNPq pela bolsa PIBIC que possibilitou a realização desta pesquisa 


\section{REFERÊNCIAS}

BATISTA, Márcia Luiza França da Silva; MENEZES, Marizilda dos Santos, O Design Gráfico e o Design Instrucional na Educação a Distância, Design, Arte e Tecnologia, São Paulo: Rosari, 2008.

CAMPOS, Gisela Belluzzo de; VASCONCELLOS, Marco A. F. de, Acaso e experimentação nos processos de criação: aproximações entre a arte moderna e o design contemporâneo, Arcos Design, vol 5, 2011

DONDIS, Donis A. Sintaxe da linguagem visual. 2. ed. São Paulo: Martins Fontes, 2003. FARBIARZ, Jackeline Lima; FARBIARZ, Alexandre; XAVIER, Guilherme, Uma abordagem dialógica do Design Instrucional, $7^{\circ}$ Congresso de Pesquisa $\&$ Desenvolvimento em Design, 2006.

FENNER, Rita de Cássia; BARCIA, Ricardo Mirando (Orientador), Engenharia da Produção. Contribuições do design na produção de software educacional. Dissertação de Mestrado. Florianópolis: Universidade Federal de Santa Catarina, 2000.

FILATRO, A., Design Instrucional Contextualizado. São Paulo: SENAC, 2004.

FILATRO, A.; PICONEZ, S. C. B., Design Instrucional Contextualizado. Disponível em http://www.abed.org.br/congresso2004/por/htm/049- -TC-B2.htm. Consultado em maio de 2010.

FUENTES, Rodolfo. A prática do design gráfico criativo. São Paulo: Editora Rosari, 2009 FUJITA, Patricia Lopes, SPINILLO, Carla Galvão, Design da informação em bulas de medicamento: análise e classificação da estrutura e apresentação gráfica de seu conteúdo textual, InfoDesign Revista Brasileira de Design da Informação 5 - 3, p.1-12, 2008.

GOMES FILHO, João. Ergonomia do objeto: sistema técnico de leitura ergonômica. São Paulo: Escrituras Editora, 2003.

HUDSON, W. Inclusive Design: Accessibility Guidelines Only Part of the Picture. Interactions, vol. 11, issue 4, July+August 2004, New York, ACM Press, p. 55-56, 2004

KEATES, S., CLARKSON, P.J., Countering design exclusion through inclusive design. In: Proceedings of the ACM Conference on Universal Usability (CCU'03), Vancouver, p. 6976, 2003.

KEATES, S., CLARKSON, P.J., HARISON, L.A., ROBINSON, P. Towards a practical inclusive design approach. In: Proceedings of the ACM Conference on Universal Usability (CCU'00), Arlington, pp. 45-52, 2000

LAKATOS, E.; MARCONI, M., Metodologia Científica. São Paulo: Ed. Atlas, 2009. LASSE, Washington Dias, Linguagem da forma/linguagem visual no âmbito do ensino de design: balizamentos teóricos; tópicos de pesquisa, ARCOS DESIGN 5, Rio de Janeiro: 2009

LÖBACH, Bernd. Desenho industrial: bases para a configuração dos produtos industriais. São Paulo: Edgar Blücher Ltda, 2001. 
LUPTON, E.; PHILLIPS, J.C., Novos Fundamentos do Design. São Paulo: Cosac Naify, 2008.

MELO, Amanda Meincke e BARANAUSKAS, M. Cecília C., Design Inclusivo de Sistemas de Informação na Web, In: BAUZER. C. et al (Ed.). WORKSHOP DE TESES DE DOUTORADO EM ANDAMENTO DO IC-UNICAMP, 2., 2006, Campinas. Anais... Campinas: IC-UNICAMP, 2006c. p. 56-57.

NEWELL, A.F., GREGOR, P., 2000, User sensitive inclusive design - in search of a new paradigm. In: Proceedings of the ACM Conference on Universal Usability (CCU'00), Arlington, p. 39-44. Tirésias: 2006. Guidelines (Inclusive Design). Disponível em: <http://www.tiresias. org/guidelines/inclusive.htm>. Acesso em: Ago. 2006.

SAMARA, Timithy, Grid: construção e desconstrução. São Paulo: Cosac Naify, 2007. Bookman, 2010. Elementos do design. Guia de estilo gráfico. Porto Alegre: Editora VILLAS-BOAS, Andre, Sobre Análise gráfica, ou Algumas estratégias didáticas para a difusão de um design crítico, ARCOS DESIGN 5, Rio de Janeiro: 2009 